\title{
Increased prevalence of salt sensitivity of blood pressure in IDDM with and without microalbuminuria
}

\author{
K. Strojek ${ }^{1}$, W. Grzeszczak ${ }^{1}$, B. Lacka ${ }^{1}$, J. Gorska ${ }^{1}$, C. K. Keller ${ }^{2}$, E. Ritz ${ }^{2}$ \\ ${ }^{1}$ Department of Internal Medicine and Occupational Diseases, Silesian Medical Academy, Zabrze, Poland \\ ${ }^{2}$ Department of Internal Medicine, Ruperto Carola University, Heidelberg, Germany
}

Summary In insulin-dependent diabetes mellitus (IDDM) elevated exchangeable sodium ( $\mathrm{Na}$ ) levels are found even in the absence of hypertension, but it is not known whether this is associated with increased sensitivity of blood pressure to sodium level. To clarify this issue we compared 30 patients with IDDM (19 without and 11 with microalbuminuria, i.e. more than $30 \mathrm{mg}$ albumin/day) and $30 \mathrm{con-}$ trol subjects matched for age, gender and body mass index. The subjects were studied on the 4 th day of a low-salt diet $(20 \mathrm{mmol} /$ day $)$ under in-patient conditions and were subsequently changed to the same diet with a high-salt supplement, yielding a total daily intake of $220 \mathrm{mmol} \mathrm{Na}$ /day. Circadian blood pressure, plasma renin activity (PRA), plasma atrial natriuretic factor ( $\mathrm{p}-\mathrm{ANF}$ ), plasma cyclic guanosine $5^{\prime}$-phosphate (p-cGMP) and urinary albumin were measured. The proportion of salt-sensitive subjects, i.e. showing increment of mean arterial pressure $\geq 3 \mathrm{mmHg}$ on high-salt diet, was $43 \%$ in diabetic patients $(50 \%$ of diabetic patients with and $37 \%$ without microalbuminuria) and $17 \%$ in control subjects $(p<0.05)$. Lying and standing PRA levels on low- or high-salt diet were significantly lower in diabetic patients than in control subjects. Salt-sensitive diabetic patients had significantly higher lying ANF on highsalt $(38.7 \pm 4.2 \mathrm{pmol} / 1$ vs $20.1 \pm 2.3 \mathrm{pmol} / 1, p<0.005)$ than on low-salt diet. The results suggest that (i) the prevalence of sodium sensitivity is high in IDDM (ii) sodium sensitivity is found even in the absence of nephropathy as indicated by albuminuria. [Diabetologia (1995) 38: 1443-1448]

Key words Insulin-dependent diabetes mellitus, blood pressure, salt sensitivity, plasma renin activity, atrial natriuretic factor, circadian blood pressure profile.
Although plasma and blood volumes are normal in normotensive and even low in hypertensive patients with diabetes mellitus $[1,2]$, exchangeable sodium is consistently increased in diabetic subjects whether or not they are given insulin treatment. The original

Received: 12 January 1995 and in revised form: 6 June 1995

Corresponding author: Dr. K. Strojek, Department of Internal Medicine and Occupational Diseases, Silesian Medical Academy, 3-go Maja 13/15, 41-800 Zabrze, Poland

Abbreviations: GFR, Glomerular filtration rate; IDDM, insulin-dependent diabetes mellitus; PRA, plasma renin activity, ANF, atrial natriuretic factor; MAP, mean arterial pressure; $p$ cGMP, cyclic guanosine 5'-phosphate. observation of Weidmann et al. [3] has meanwhile been confirmed by subsequent authors. Not only is extracellular and specifically interstitial volume increased but in hypertensive individuals blood pressure is also exquisitely salt-sensitive [4]. This observation points to a pathogenetic role for sodium in the maintenance, and perhaps even in the initiation of high blood pressure. In diabetic subjects with hypertension and nephropathy, blood pressure correlates positively with exchangeable sodium [3-5] and exchangeable sodium is progressively elevated in more advanced stages of nephropathy [2].

Although there is a wealth of information on exchangeable sodium and sodium handling in diabetic patients with or without hypertension, the issue of whether blood pressure is sodium-sensitive has been 
Table 1. Clinical characteristics of patients

\begin{tabular}{|c|c|c|c|c|c|c|}
\hline & $\begin{array}{l}\text { Age } \\
\text { (years) }\end{array}$ & $\begin{array}{l}\mathrm{BMI} \\
\left(\mathrm{kg} / \mathrm{m}^{2}\right)\end{array}$ & $\begin{array}{l}\text { Duration } \\
\text { (years) }\end{array}$ & $\begin{array}{l}\mathrm{HbA}_{1 \mathrm{c}} \\
(\%)\end{array}$ & $\begin{array}{l}\text { Daily inulin } \\
\text { (U/kg) }\end{array}$ & $\begin{array}{l}\text { cInulin } \\
\left(\mathrm{ml} \times \mathrm{min}^{-1}\right. \\
\left.\times 1.73 \mathrm{~m}^{-2}\right)\end{array}$ \\
\hline $\begin{array}{l}\text { Normoalbuminuric } \\
(n=19)\end{array}$ & $30.8 \pm 1.8$ & $23.6 \pm 0.4$ & $5.4 \pm 1.1$ & $7.5 \pm 0.3$ & $0.6 \pm 0.04$ & $118 \pm 5.0$ \\
\hline $\begin{array}{l}\text { Microalbuminuric } \\
(n=16)\end{array}$ & $33.5 \pm 1.6$ & $23.5 \pm 0.7$ & $13.5 \pm 2.2$ & $7.8 \pm 0.2$ & $0.8 \pm 0.06$ & $136 \pm 5.0$ \\
\hline
\end{tabular}

Data are given as mean \pm SEM

examined only in hypertensive patients with diabetes [4]. The question of whether blood pressure is also sodium-sensitive in normotensive diabetic patients is of both theoretical and practical interest.

On the one hand "antinatriuretic forces" appear to operate in patients with diabetes, as indicated by increased exchangeable sodium $[1,2]$ and by inappropriate responses of volume controlling hormones to dynamic manoeuvres such as water immersion $[6,7]$. This may be due to the known antinatriuretic effect of insulin as originally shown by DeFronzo et al. [8] and confirmed by subsequent studies $[9,10]$. Alternatively, it may be the result of increased proximal tubular reabsorption of sodium via the glucose/sodium cotransporter.

On the other hand, the issue of whether modification of dietary sodium can alter blood pressure in the diabetic patient, as suggested by Dodson et al. [11], is also of potential clinical importance.

To address this issue we designed a parallel group sequential study. Patients with IDDM (insulin-dependent diabetes mellitus) in good metabolic control were compared with non-diabetic control subjects of similar age, gender and body mass index. Patients were studied sequentially on an identical low-salt diet ( $20 \mathrm{mmol} \mathrm{Na} /$ day) without and subsequently with a sodium supplement to yield a total daily $\mathrm{NaCl}$ intake of $220 \mathrm{mmol} /$ day. Blood pressure was measured by continuous blood pressure recording (Medilog system, Oxford, UK) under in-patient conditions.

\section{Patients and methods}

The study protocol was approved by the ethical committees of the Universities of Katowice and Heidelberg; all subjects gave written informed consent. The study was carried out in the Department of Internal Medicine of the Silesian Medical Academy, Zabrze, Poland. We approached diabetic patients who were normotensive according to World Health Organization (WHO) criteria, i.e. with casual blood pressure measuring less than $140 / 90 \mathrm{mmHg}$. The study was designed to include a total of 30 patients with 30 matched control subjects. Upon completion of this study we included a further five microalbuminuric diabetic patients without matched control subjects.
The data relevant to the patients' clinical characteristics are given in Table 1. Habitual protein and sodium intakes were estimated from five $24-h$ urine collections. We excluded all patients who had a serum creatinine level greater than $110 \mu \mathrm{mol} / \mathrm{l}$. Albumin excretion was assessed by radioimmunometric assay from five 24-h urine collections. Patients were classified as being microalbuminuric if all collections contained more than $30 \mathrm{mg} / 24 \mathrm{~h}$ albumin, otherwise patients were classified as not microalbuminuric. Patients with inconsistent values were not admitted to the study. From collaborators in the hospital we selected 30 individuals who were matched for age, gender and BMI $\left(\mathrm{kg} / \mathrm{m}^{2}\right)$ to the initial cohort of diabetic patients. The mean age of control subjects was $28.2 \pm 0.8$ years; 16 were male, 14 were female; BMI, $23.1 \pm 0.54 \mathrm{~kg} / \mathrm{m}^{2}$. All were examined to verify the presence of normal endogenous creatinine clearance, normal blood pressure according to WHO criteria and absence of albuminuria. Physical and laboratory examinations excluded major diseases, specifically diabetes mellitus.

Study design. All diabetic patients and control subjects were examined under in-patient conditions on the metabolic ward. They received a pre-cooked diet with defined $\mathrm{NaCl}$ content, confirmed by ashing and chemical analysis, i.e. $20 \mathrm{mmol}$ $( \pm 1) \mathrm{mmol} \mathrm{Na}$ /day. All individuals received the same amount of food. The diet provided $130 \mathrm{~kJ} \cdot \mathrm{kg}^{-1} \cdot \mathrm{day}^{-1}$, including $250 \mathrm{~g}$ complex carbohydrates/day, $45 \mathrm{~g}$ fat/day and $35 \mathrm{mmol}$ potassium/day. The actual amount consumed was quantified by reweighing. Urinary sodium excretion was monitored by daily 24-h urine collections. Patients adjusted their insulin by selfmeasurement of blood glucose. During the study a median daily insulin dose of $0.75 \mathrm{IU} \cdot \mathrm{kg}^{-1} \cdot$ day $^{-1}$ was administered (range 0.55-0.94) and there was no specific difference between the low-salt and the high-salt periods (median 0.73 vs $0.76 \mathrm{IU} \cdot \mathrm{kg}^{-1} \cdot$ day $^{-1}$ ). High-salt intake was achieved by adding slow-release sodium chloride tablets providing a daily $\mathrm{NaCl}$ intake of $220 \mathrm{mmol} /$ day. Continuous blood pressure recording was carried out on the 4 th day of each study period. Blood for chemical measurements was obtained on the 1 st and 4 th day of each study period.

Measurements. Continuous blood pressure recordings were carried out using the Medilog ABP System. Night-time pressure was defined as blood pressure between 22.00 and 06.00 hours. Blood and urine chemistries were measured using Auto-analyser techniques.

Haemoglobin $\mathrm{A}_{1 \mathrm{c}}$ was measured using the DCA 2000 Autoanalyser (Bayer Diagnostics, Elkhart, Ind., USA). Haematocrit was measured by centrifugation. Plasma renin activity (PRA) and plasma aldosterone were measured by radioimmunoassay (RIA) according to Kokot [12], plasma atrial natriuretic factor (ANF) by RIA [13], and plasma cyclic Guanosine $5^{\prime}$ phosphate (cGMP) with RIA [14]. Urinary albumin 
Table 2. Comparison of low- and high-salt periods

\begin{tabular}{|c|c|c|c|c|}
\hline \multirow[b]{2}{*}{$n$} & \multicolumn{2}{|l|}{ Low-salt period } & \multicolumn{2}{|l|}{ High-salt period } \\
\hline & $\begin{array}{l}\text { Diabetic subjects } \\
35\end{array}$ & $\begin{array}{l}\text { Control subjects } \\
30\end{array}$ & $\begin{array}{l}\text { Diabetic subjects } \\
35\end{array}$ & $\begin{array}{l}\text { Control subjects } \\
30\end{array}$ \\
\hline Mean blood glucose $(\mathrm{mmol} / \mathrm{l})$ & $7.83 \pm 0.97$ & - & $7.78 \pm 0.89$ & - \\
\hline Haematocrit $(\%)$ & $43.0 \pm 0.4$ & $42.7 \pm 0.5$ & $40.1 \pm 0.6$ & $41.6 \pm 0.4$ \\
\hline Plasma-Na (mmol/l) & $133 \pm 1.6$ & $130 \pm 1.5$ & $137 \pm 1.8$ & $135 \pm 1.9$ \\
\hline
\end{tabular}

Data are given as mean \pm SEM

a Difference high- vs low-salt period; $p<0.001$ (Wilcoxon test for paired differences)

Table 3. Blood pressure ( $\mathrm{mmHg}$ ) during low- and high-salt periods in diabetic patients

\begin{tabular}{|c|c|c|c|c|c|c|c|c|c|c|}
\hline \multirow[t]{2}{*}{ Group } & \multirow{2}{*}{$\begin{array}{l}\text { Salt } \\
\text { intake }\end{array}$} & \multicolumn{3}{|c|}{ Mean arterial pressure } & \multicolumn{3}{|c|}{ Systolic blood pressure } & \multicolumn{3}{|l|}{ Heart rate } \\
\hline & & $\overline{24 \mathrm{~h}}$ & Day & Night & $24 \mathrm{~h}$ & Day & Night & $24 \mathrm{~h}$ & Day & Night \\
\hline $\begin{array}{l}\text { Diabetic } \\
\text { subjects } \\
(n=35)\end{array}$ & $\begin{array}{l}\text { low } \\
\text { high }\end{array}$ & $\begin{array}{l}80.9 \pm 1.0 \\
82.1 \pm 1.4 \\
\end{array}$ & $\begin{array}{l}82.6 \pm 1.0 \\
84.8 \pm 1.4^{a} \\
c\end{array}$ & $\begin{array}{l}73.6 \pm 1.3 \\
74.2 \pm 1.5\end{array}$ & $\begin{array}{l}111 \pm 1.8 \\
114 \pm 1.9^{b} \\
c\end{array}$ & $\begin{array}{l}113 \pm 1.7 \\
117 \pm 1.9^{b} \\
c\end{array}$ & $\begin{array}{l}103 \pm 2.4 \\
105 \pm 2.4\end{array}$ & $\begin{array}{l}81.9 \pm 1.5 \\
80.6 \pm 1.3\end{array}$ & $\begin{array}{l}84.2 \pm 1.4 \\
82.7 \pm 1.3\end{array}$ & $\begin{array}{l}71.8 \pm 1.4 \\
71.6 \pm 1.7\end{array}$ \\
\hline $\begin{array}{l}\text { Control } \\
\text { subjects } \\
(n=30)\end{array}$ & $\begin{array}{l}\text { low } \\
\text { high }\end{array}$ & $\begin{array}{l}81.1 \pm 1.4 \\
80.3 \pm 1.5\end{array}$ & $\begin{array}{l}82.3 \pm 1.4 \\
82.2 \pm 1.4\end{array}$ & $\begin{array}{l}74.0 \pm 1.7 \\
72.6 \pm 1.9\end{array}$ & $\begin{array}{l}114 \pm 2.1 \\
115 \pm 2.1\end{array}$ & $\begin{array}{l}113 \pm 2.2 \\
117 \pm 2.1\end{array}$ & $\begin{array}{l}107 \pm 2.8 \\
108 \pm 3.0\end{array}$ & $\begin{array}{l}85.6 \pm 1.8 \\
83.4 \pm 1.5\end{array}$ & $\begin{array}{l}88.0 \pm 1.4 \\
85.9 \pm 1.3\end{array}$ & $\begin{array}{l}73.5 \pm 2.1 \\
72.3 \pm 1.7\end{array}$ \\
\hline
\end{tabular}

Data are given as mean \pm SEM

${ }^{a} p<0.05$ high-salt vs low-salt period;

b $p<0.01$ high-salt vs low-salt period;

c $p<0.05$ blood pressure high-low in diabetic vs control subjects

by RIA according to Keen [15], glomerular filtration was assessed using steady-state inulin clearance [16].

\section{Statistical analysis}

Data are given as mean \pm SEM (or median and range if they were not normally distributed). Comparisons were made using Wilcoxon's test for paired intra-individual differences (i. e. between low- and high-salt phases) or Wilcoxon's test for random samples for comparisons between groups.

\section{Results}

Baseline data. Table 2 compares some of the relevant parameters on the 4 th day of the low-salt and highsalt periods, respectively. The data document good compliance to dietary $\mathrm{Na}$ intake and similar metabolic control during the low-salt and high-salt periods, respectively. Haematocrit (indirect evidence of volume expansion) was lower on the high-salt diet. Plasma sodium was unchanged and potassium somewhat lower on high-salt diet. Urine was tested for glycosuria which was negative in all samples.

Blood pressure measurements. As seen in Table 3, there was no significant difference in the various blood pressure measurements between diabetic patients and control subjects. However, the increment in blood pressure upon transition from low- to high-salt diet was significantly higher with respect to $24-\mathrm{h}$ and daytime mean arterial pressure (MAP) and 24-h daytime systolic blood pressure, respectively $(p<0.05)$.

Blood pressure according to microalbuminuria. Table 4 shows a clear difference between normoalbuminuric and microalbuminuric diabetic patients. Upon transition from low- to high-salt diet the increments in systolic blood pressure and the percent decrease of nocturnal blood pressure were significant only in microalbuminuric subjects. In microalbuminuric patients a significantly greater night-time decrease of blood pressure was noted upon transition from low- to high-salt diet $(p<0.01)$.

Treating the albumin excretion rate $(\mathrm{mg} / 24 \mathrm{~h})$ as a continuous variable, a significant correlation was noted between albuminuria and (i) daytime MAP $(r=0.41 ; p<0.05)$ and (ii) percent night-time decrease of MAP $(r=0.57, p<0.001)$. Microalbuminuric patients did not have impaired renal function. Glomerular filtration rate (GFR) as measured by steady-state inulin clearance was $125 \pm 3.9 \mathrm{ml} \times \mathrm{min}^{-1}$ $\times 1.73^{\mathrm{m}-2}$ in the 35 diabetic subjects. It was $118 \pm$ $5.0 \mathrm{ml} \times \mathrm{min}^{-1} \times 1.73^{\mathrm{m}-2}$ in the normoalbuminuric and $136 \pm 5.0 \mathrm{ml} \cdot \mathrm{min}^{-1} \times 1.73 \mathrm{~m}^{-2}$ in the microalbuminuric individuals. Salt-sensitive and salt-resistant individuals did not differ with respect to inulin clearance, i.e. $131 \pm 5.3$ vs $123 \pm 5.1 \mathrm{ml} \times \mathrm{min}^{-1} \times 1.73^{-2}$. 
Table 4. Comparison of blood pressure response to high salt diet between normoalbuminuric and microalbuminuric IDDM patients

\begin{tabular}{llccc}
\hline Group & Salt intake & $\begin{array}{l}\text { MAP } \\
(\mathrm{mmHg})\end{array}$ & $\begin{array}{l}\text { Systolic pressure } \\
(\mathrm{mmHg})\end{array}$ & $\begin{array}{l}\text { Nocturnal decrease of } \\
\text { systolic blood pressure (\%) }\end{array}$ \\
\hline $\begin{array}{l}\text { Normoalbuminuric } \\
(n=19)\end{array}$ & low & $78.7 \pm 1.4$ & $109 \pm 2.7$ & $14.4 \pm 2.8$ \\
& high & $80.5 \pm 1.8$ & $112 \pm 2.6$ & $11.3 \pm 1.4$ \\
Microalbuminuric & difference high vs low & $0.8 \pm 1.3$ & $2.5 \pm 1.5$ & $-3.1 \pm 2.4$ \\
$(n=16)$ & low & $82.4 \pm 1.5$ & $113 \pm 2.3$ & $5.4 \pm 2.5$ \\
& high & $84.0 \pm 1.6$ & $117 \pm 2.5^{\mathrm{a}}$ & $13.9 \pm 3.0^{\mathrm{a}}$ \\
\hline
\end{tabular}

Data are given as mean \pm SEM

a $p<0.05$ low salt vs high salt period

b $p<0.01$ microalbuminuric vs normoalbuminuric diabetic patients

Table 5. Categorization of salt sensitivity

\begin{tabular}{llll}
\hline & $n$ & & Percent salt sensitive \\
\hline Diabetic subjects & 35 & $15 / 35$ & $43^{\mathrm{a}}$ \\
normoalbuminuric & 19 & $7 / 19$ & 37 \\
microalbuminuric & 16 & $8 / 16$ & $50^{\mathrm{a}}$ \\
Control subjects & 30 & $5 / 25$ & 17 \\
\hline
\end{tabular}

Calculated according to Sharma et al. [17], i.e., increment of MAP by $3 \mathrm{mmHg}$ on high-salt diet

${ }^{a} p<0.05$ control subjects vs diabetic patients

Salt sensitivity. The patients were categorized according to Sharma et al. [17], i.e. classified as salt-sensitive if the increment of 24-h MAP on high-salt diet exceeded $3 \mathrm{mmHg}$. According to this definition, $43 \%$ of diabetic patients and $17 \%$ of the control subjects were salt-sensitive ( $p<0.05$ by chi-square test) (Table 5). The proportion tended to be greater in diabetic patients with microalbuminuria, but the difference between normoalbuminuric and microalbuminuric patients was not statistically significant, presumably as a result of the small sample size.

When the cut-off of a 4-mmHg increase in MAP upon transition from low- to high-salt diet was chosen, there was still a significant difference in the proportion of salt-sensitive individuals between control subjects (4 of 30 ) and diabetic patients (15 of 35; $p<0.05$ ), showing that higher salt sensitivity can be demonstrated irrespective of the categorisation criteria.

This is further emphasised by the fact that on a high salt diet 24-h MAP was significantly higher in salt-sensitive $(84.7 \pm 1.5 \mathrm{mmHg})$ compared to salt-resistant diabetic patients $(80.1 \pm 1.7 ; p<0.05)$.

Sodium-regulating hormones. Table 6 summarizes the change of PRA, ANF and plasma cGMP after night rest (lying) and $30 \mathrm{~min}$ standing.

PRA was consistently lower in diabetic patients compared to control subjects, both on low-salt and on high-salt diet in either the lying or standing position. This finding documents suppressed renin activity. The plasma aldosterone values paralleled those of PRA.

$\mathrm{ANF}$, and less markedly plasma cGMP concentrations, were higher when lying as compared to standing. High-salt intake increased ANF significantly, both in diabetic patients and in control subjects. This was accompanied by a directionally similar, but statistically not significant, change in plasma cGMP concentration.

Average lying ANF in salt-sensitive diabetic patients was $20.9 \pm 2.3 \mathrm{pmol} / \mathrm{l}$ on low- and $38.7 \pm$ $4.2 \mathrm{pmol} / 1$ on high-salt $(p<0.001)$ vs $20.1 \pm 2.3 \mathrm{pmol} / 1$ and $29.1 \pm 2.4 \mathrm{pmol} / \mathrm{l}(p<0.001)$ in salt-resistant diabetic patients, respectively. The lying ANF concentrations on high-salt diet were significantly $(p<0.05)$

Table 6. Volume regulating hormones in lying and standing position on either low or high salt intake

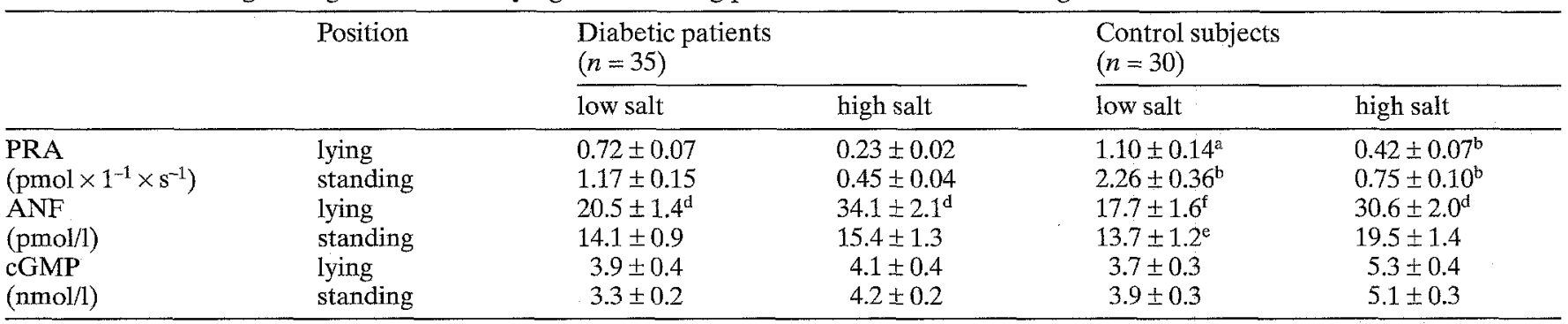

Data are mean \pm SEM.

${ }^{a} p<0.05$ diabetic patients vs control subjects; ${ }^{\mathrm{b}} p<0.01$ diabetic patients vs control subjects; ${ }^{\mathrm{c}} p<0.05$ lying vs standing position;

${ }^{\mathrm{d}} p<0.001$ lying vs standing position; ${ }^{\mathrm{e}} p<0.005$ low salt vs high salt; ${ }^{\mathrm{f}} p<0.001$ low salt vs high salt 
different between salt-sensitive and salt-resistant diabetic patients.

\section{Discussion}

This study was performed in normotensive IDDM patients with or without incipient nephropathy, i.e. microalbuminuria. The primary result is documentation that the proportion of these individuals whose blood pressure is salt-sensitive is greater than in nondiabetic control subjects of similar age, gender and BMI. Although salt-sensitive blood pressure was encountered somewhat more often in microalbuminuric patients, sodium sensitivity was not restricted to this group of patients and was also noted in a high proportion of diabetic patients with normal albumin excretion. In a pilot experiment we found that on the 4 th day of the low-salt diet, individuals were in salt equilibrium, i.e. urinary sodium excretion on day 4 and day 5 did not differ more than $15 \%$. We had considered randomly changing the patients from low- to high-salt intake or vice versa; however we decided on a sequential order design, because longer duration of an experiment with a washout period in between might have jeopardized the constancy of metabolic control. Compliance with the diet was excellent, as measured by urinary sodium excretion. Metabolic control was identical during the two periods in the diabetic patients as documented by comparable average glucose measurements on the 4 th day of the low-salt and high-salt periods, respectively. In a pilot study we assessed the reproducibility of the Medilog 24-h blood pressure measurements in diabetic subjects. After repeated measurement the coefficient of variation (MAP) did not exceed $3 \pm 0.2 \%$ (corresponding to $2.4 \pm 0.16 \mathrm{mmHg}$ ) in ten individuals on four occasions. We specifically looked for an order effect and found no significant difference between the first measurement $(100 \%)$ and the fourth measurement $(96.8 \%)$.

All of the diabetic patients were normotensive according to WHO criteria. Their average 24-h MAP was not significantly different from that of control subjects.

Salt-sensitivity was assessed according to several different criteria. We adopted the procedure used by Sharma et al. [17] and classified as salt-sensitive those patients in whom the increment of MAP on high-salt intake exceeded $3 \mathrm{mmHg}$. According to this definition the proportion of salt-sensitive individuals was significantly higher in the group of diabetic patients than in non-diabetic control subjects. This was particularly true for diabetic patients with microalbuminuria.

Because the cut-off of $3 \mathrm{mmHg}$ MAP was somewhat arbitrary, we chose alternative cut-offs, e.g. 3.5, 4 and $4.5 \mathrm{mmHg}$. When these alternative cut-offs were adopted, the difference continued to be significant.

Because the approach of Sharma et al. [17] has not been universally accepted, we also compared 24-h systolic blood pressures and MAP on high-salt diet in individuals classified as salt-sensitive compared to individuals classified as salt-resistant. The difference was statistically significant. We also compared the difference in average 24-h systolic blood pressure and 24-h MAP between diabetic patients and control subjects. In control subjects the response to a dietary $\mathrm{NaCl}$ load was more heterogeneous, since some subjects showed a decrease and others an increase in blood pressure in response to high salt diet, as previously reported by Luft et al. [18]. When we compared the average difference of 24-h systolic blood pressure on high-salt vs low-salt diets between diabetic patients and control subjects, it was statistically significant $(p<0.05)$. These approaches document that the hypothesis of higher prevalence of salt-sensitivity in diabetes is proven to be true, independent of the criteria used to define it.

Although the proportion of salt-sensitive individuals was not higher among microalbuminuric diabetic patients, a statistically significant relation was found between urinary albumin excretion rate and increment in 24-h MAP upon transition from low- to high-salt diet in diabetic patients. This finding suggests a role for renal damage in this phenomenon. We ascribe the failure to find a significant difference between microalbuminuric and normoalbuminuric patients to the limited number of patients investigated. No significant correlation was noted between BMI, duration of diabetes and daily insulin dose and increment in 24-h MAP upon transition from low- to high-salt diet in diabetic patients (data not reported).

A relation between exchangeable sodium and blood pressure has been observed by Feldt-Rasmussen et al. [2] in various stages of diabetic nephropathy. Furthermore, blood pressure increased after high salt intake [3]. The question arises whether abnormal (renal) handling of sodium is involved in the genesis of this phenomenon. Even normotensive diabetic patients are known to have increased exchangeable sodium [1] suggesting increased tubular sodium retention. A volume-expanded state in the diabetic patients on high sodium intake is suggested by significantly lower haematocrit values. Salt-sensitive diabetic patients have significantly lower supine PRA on a high-salt diet than do salt-resistant diabetic patients. Furthermore, lying ANF concentrations were significantly higher in salt-sensitive diabetic patients. Obviously, higher ANF levels would be compatible with either a compensatory increase in ANF in response to ANF resistance or increased ANF secretion in response to greater atrial stretch. Our findings cannot directly distinguish between these possibilities, but the concomitantly lower PRA concentra- 
tions are consistent with a state of relative central volume expansion on high salt, at least in the supine position. Our observation of generally lower PRA in diabetic patients, compared to the control subjects, regardless of dietary sodium intake and of body position is in agreement with previous observations [19, 20]. We emphasize that the method used excluded artefacts from high pro-renin levels.

Apart from volume expansion, an alternative explanation could be increased sympathetic nerve activity in response to salt load. This had previously been observed by Campese et al. [21] in some patients with primary hypertension. We did not study sympathetic nerve activity in detail, but noted that heart rate did not change.

The question could be raised whether such minor sodium-dependent increments in blood pressure are relevant to patient management. In the patients with microalbuminuria, recent evidence suggests that blood pressure-induced damage begins at blood pressure levels far below the conventional ceiling of normotension [22]. In the pre-hypertensive stage blood pressure is sodium-sensitive in a high proportion of diabetic patients. Whether efforts to reduce dietary salt intake $[23,24]$ with the attendant reduction in quality of life are justified will have to be investigated in future trials.

Acknowledgement. This work was supported by Grant No. NN 560-54/94 from the Silesian Medical Academy in Katowice and a grant of the Else Kröner Stiftung.

\section{References}

1. Weidmann P, Beretta-Piccoli C, Trost BN (1987) Pressor factors and responsiveness in hypertension accompanying diabetes mellitus. Hypertension 7 [Suppl 2]: 33-42

2. Feldt-Rasmussen B, Mathiesen ER, Deckert Tet al. (1987) Central role for sodium in the pathogenesis of blood pressure changes independent of angiotensin, aldosterone and catecholamines in type 1 (insulin-dependent) diabetes mellitus. Diabetologia 30: 610-617

3. Weidmann P, Beretta-Piccoli C, Keusch G et al. (1979) Sodium volume factor, cardiovascular reactivity and hypotensive mechanism of diuretic therapy in mild hypertension associated with diabetes mellitus. Am J Med 67: 779--784

4. Tuck M, Corry D, Trujillo A (1990) Salt sensitive blood pressure and exaggerated vascular reactivity in the hypertension of diabetes mellitus. Am J Med 88: 210-216

5. O'Hare JA, Ferris JB, Brady D, Twomey B, O'Sullivan DJ (1985) Exchangeable sodium and renin in hypertensive diabetic patients with and without nephropathy. Hypertension 7 [Suppl 2]: II-43-II-48

6. Trevisan R, Fioretto P, Semplicini A et al. (1990) Role of insulin and atrial natriuretic peptide in sodium retention in insulin-treated IDDM patients during isotonic volume expansion. Diabetes 39: 289-298
7. O'Hare JP, Roland JM, Walters G, Corral RJM (1986) Impaired sodium excretion in response to volume expansion induced by water immersion in insulin dependent diabetes mellitus. Clin Sci 71: 403-409

8. DeFronzo RA, Cooke CR, Andres R, Faloona GR, Davis PJ (1975) The effect of insulin on renal handling of sodium, potassium, calcium, and phosphate in man. J Clin Invest 55: $845-855$

9. Campbell PJ, Carlson MG (1993) Impact of obesity on insulin action in NIDDM. Diabetes 42: 405-410

10. Rocchini AP, Katch V, Kveselis D et al. (1989) Insulin and renal sodium retention in obese adolescents. Hypertension 14: $367-374$

11. Dodson PM, Beevers M, Hallworth R, Webberley MJ, Fletcher RF, Taylor KG (1989) Sodium restriction and blood pressure in hypertensive type II diabetics: randomized blind controlled and crossover studies of moderate sodium restriction and sodium supplementation. BMJ 298: $227-230$

12. Kokot F, Stupnicki R (1985) Radioimmunological and radiocompetition methods used in clinical medicine. (in Polish) PZWL Waszawa

13. Kokot F, Grzeszczak W, Wiecek A (1989) Water immersion induced alteration of atrial natriuretic peptide in patients with non-inflammatory acute renal failure. Nephrol Dial Transplant 4: 619-695

14. Siragy HM, Ibrahim MM, Jaffa AA, Mayfield R, Margolius HS (1994) Rat renal interstitial bradykinin, PG E2 and cyclic $3^{\prime} 5^{\prime}$ guanosine monophosphate. Effects of altered sodium intake. Hypertension 23: 1068-1075

15. Keen H (1963) An immunoassay method for urinary albumin at low concentrations. Lancet 2: 913-916

16. Schmid M, Mann JFE, Stein G et al. (1990) Natriuresis pressure relationship in polycystic kidney disease. J Hypertension 8: 277-283

17. Sharma AM, Schatenfroh S, Kribben A, Distler A (1989) Reliability of salt-sensitivity testing in normotensive subjects. Klin Wochenschr 67: 632-634

18. Luft FC, Miller JZ, Weiberger MH, Christian JC, Skrabal F (1988) Genetic influences on the response to dietary salt reduction, acute salt loading, or salt depletion in humans. J Cardiovasc Pharmacol 12 [Suppl 3]: S 49-S55

19. Sparagana M (1975) Hyporeninemic hypoaldosteronism with diabetic glomerulosclerosis. Biochem Med 14: 93-103

20. Tuck ML, Sambhi MP, Levin L (1979) Hyporeninemic hypoaldosteronism in diabetes mellitus. Studies of the autonomic nervous system's control of renin release. Diabetes 28: $237-241$

21. Campese VM, Karubian F, Cheron J, Parise M, Sarkies N, Bigazzi R (1993) Pressor reactivity to norepinephrine and angiotensin in salt sensitive hypertensive patients. Hypertension 21 (3): 301-307

22. Osterby R (1995) Microalbuminuria in diabetes mellitus is there a structural basis? Nephrol Dial Transplant 10: 24 26

23. Report of WHO Study Group (1994) Prevention of diabetes mellitus. WHO Technical Report Series 844. World Health Organization, Geneva

24. American Diabetes Association (1989) Standards of medical care for patients with diabetes mellitus. Diabetes Care 12: $365-368$ 